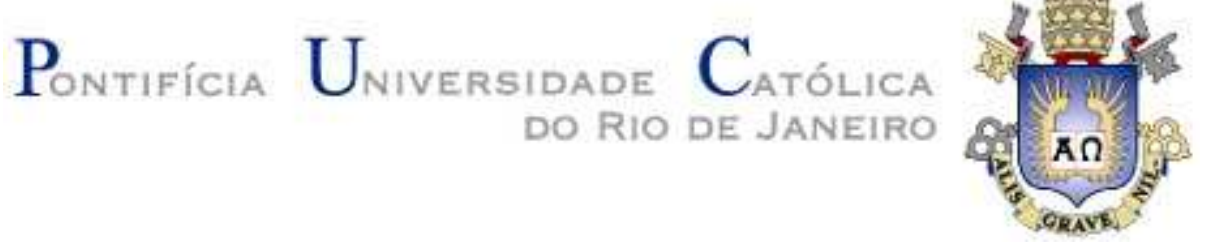

Claudia Torres Volpon

\begin{abstract}
Alinhamento estratégico da responsabilidade sócio-ambiental corporativa no caso de empresas que atuam em redes de relacionamento: Resultados de pesquisa na Petrobras
\end{abstract}

Dissertação de Mestrado

Dissertação apresentada ao Programa de Pós-Graduação em Administração de Empresas da PUC-Rio como requisito parcial para a obtenção do grau de Mestre em Administração.

Orientadora: Profa. Dra. T. Diana L. v. A. de Macedo-Soares 
Claudia Torres Volpon

\title{
Alinhamento estratégico da responsabilidade sócio-ambiental corporativa no caso de empresas que atuam em redes de relacionamento: Resultados de pesquisa na Petrobras
}

\begin{abstract}
Dissertação apresentada ao Programa de Pós-Graduação em Administração de Empresas da PUC-Rio como requisito parcial para a obtenção do grau de Mestre em Administração. Aprovada pela Comissão Examinadora abaixo assinada.
\end{abstract}

Prof ${ }^{a}$. Dra. Teresia Diana Lewe van Aduard de Macedo-Soares

Orientadora

Departamento de Administração, PUC-Rio

Prof. Mário Soares Pinto Departamento de Administração, PUC-Rio

Prof ${ }^{\text {a }}$ Deborah Moraes Zouain

FGV

Prof. João Pontes Nogueira Vice-Decano de Pós-Graduação do CCS, PUC-Rio 
Todos os direitos reservados. É proibida a reprodução total ou parcial do trabalho sem autorização da universidade, do autor e da orientadora.

\section{Claudia Torres Volpon}

Graduou-se em Administração na Universidade Federal Fluminense (UFF) em 2003. Atuou no setor de Telecomunicações durante três anos e, desde 2006, trabalha na Petrobras na área de exploração e produção de petróleo.

Ficha catalográfica

Volpon, Claudia Torres

Alinhamento estratégico da responsabilidade sócioambiental corporativa no caso de empresas que atuam em redes de relacionamento: resultados de pesquisa na Petrobras / Claudia Torres Volpon ; orientador: T. Diana L. v. A. de Macedo-Soares. - Rio de Janeiro : PUC-Rio, Departamento de Administração, 2006.

171 f. ; $30 \mathrm{~cm}$

Dissertação (mestrado) - Pontifícia Universidade Católica do Rio de Janeiro, Departamento de Administração

Inclui bibliografia

1. Administração - Teses. 2. Estratégia. 3. Alianças. 4. Responsabilidade social e ambiental. 5. Energia. 6. Petrobras. I. Macedo-Soares, T. Diana L. V. A. de. II. Pontifícia Universidade Católica do Rio de Janeiro. Departamento de Administração. III. Título. 


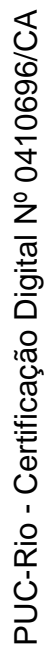

À minha família e amigos,

pela compreensão e apoio. 


\section{Agradecimentos}

Aos meus pais, pelo carinho e apoio incondicional.

Ao meu marido, Leandro, por seu amor e companheirismo, pelas palavras de estímulo e entusiasmo e por sua compreensão.

À minha orientadora Prof $\stackrel{a}{\text { a }}$ T. Diana L. v. A. de Macedo-Soares, pela paciência, dedicação e confiança com as quais soube ensinar e estimular a importância de melhorarmos constantemente.

Aos meus colegas de mestrado da PUC-Rio que conseguiram transformar momentos de dificuldade e ansiedade em uma das melhores experiências que já tive.

Aos profissionais da Petrobras, em especial do Cenpes, por sua paciência e colaboração, com suas respostas ao questionário, críticas e sugestões, que ajudaram profundamente nesta pesquisa. 


\section{Resumo}

Volpon, Claudia Torres; Macedo-Soares, Teresia Diana Lewe van Aduard de. Alinhamento estratégico da responsabilidade sócio-ambiental corporativa no caso de empresas que atuam em redes de relacionamento: Resultados de pesquisa na Petrobras. Rio de Janeiro, 2006. 171p. Dissertação de Mestrado - Departamento de Administração, Pontifícia Universidade Católica do Rio de Janeiro.

As configurações em redes são cada vez mais importantes para a performance e a conduta das empresas na maioria das indústrias. Entretanto, as suas implicações estratégicas sob a ótica da responsabilidade social e ambiental têm sido não somente pouco investigadas no âmbito acadêmico, como também pouco consideradas no planejamento estratégico das empresas. Neste contexto, a presente pesquisa pretende contribuir ao investigar o impacto das alianças e redes de relacionamento na gestão estratégica da Petrobras, considerando a dimensão sócio-ambiental. O estudo teve como foco a Petrobras, maior empresa de energia do Brasil, devido ao desafio de sustentar sua vantagem competitiva através de uma postura socialmente responsável. De acordo com a metodologia de estudo de caso de Yin, foi adotada a estratégia de triangulação dos métodos. Assim, dados foram coletados por meio de investigação documental /telematizada, formulário estruturado e entrevistas. A interpretação e análise dos dados foram realizadas com base no referencial teórico pertinente a área de estudo e auxílio do modelo genérico integrativo de Macedo-Soares. Os resultados evidenciam que a análise na ótica relacional, que leva em conta as implicações estratégicas das redes nas quais a empresa atua, agrega valor à análise tradicional, contribuindo com novos insights para a tomada de decisão estratégica da Petrobras, considerando a sua orientação sócio-ambiental.

\section{Palavras-chave}

Estratégia, Alianças, Responsabilidade Social e Ambiental, Petrobras, Energia. 


\section{Abstract}

Volpon, Claudia Torres; Macedo-Soares, Teresia Diana Lewe van Aduard de (Advisor). Strategic alignment of social and environmental corporate responsibility in case of firms embedded in alliance networks: Results of research at Petrobras. Rio de Janeiro, 2006. 171p. MSc. Thesis - Pontifical Catholic University of Rio de Janeiro, Business Administration Department/IAG.

Network configurations have become increasinly important for the conduct and performance of firms in most industries. However, its strategic implications under the social responsibility perspective have rarely been taken into account in the academic literature as well as in corporate strategic planning. Thus, the present research contributes to this field by investigating the impact of alliances and networks on Petrobras' strategic management, considering both social and environmental view. This study focuses on Petrobras, a major brasilian energy firm, due to its challenge to sustain a competitive advantage through a social responsible posture. According to Yin's case study method, multiple sources of evidence were adopted, with data converging in triangulation fashion. Therefore, data collection consisted on documental investigation, survey of management's perceptions and open-ended interviews. Data analysis and interpretation were based on theoretical references pertinent to the research area and MacedoSoares's generic integrative framework. The results higlight that the relational view, which considers the strategic implications from the networks, adds value to traditional analysis and provides new insights for Petrobras's decision-making, considering its social and environmental orientation.

\section{Keywords}

Strategy, Alliances, Social and Environmental Responsibility, Petrobras, Energy. 


\section{Sumário}

1 Introdução 14

1.1 Problema 16

$\begin{array}{ll}1.2 \text { Objetivos } & 17\end{array}$

$\begin{array}{ll}\text { 1.2.1 Objetivo da pesquisa maior } & 17\end{array}$

$\begin{array}{ll}1.2 .2 \text { Objetivo desta pesquisa } & 17\end{array}$

$\begin{array}{lr}1.3 \text { Relevância do estudo } & 18\end{array}$

$\begin{array}{ll}1.4 \text { Delimitação do estudo } & 19\end{array}$

2 Referencial Teórico $\quad 21$

2.1 Conceitos Gerais 21

2.2 Alianças Estratégicas $\quad 24$

2.3 Responsabilidade sócio-ambiental 25

2.3.1 Responsabilidade sócio-ambiental e performance da
empresa

2.3.2 Responsabilidade sócio-ambiental no contexto
empresarial

2.4 Alianças estratégicas e Responsabilidade sócio-ambiental 34

2.5 Modelo Macedo-Soares (2002) para Análise da Adequação

Estratégica

2.6 Modelo Macedo-Soares (2002) para Análise Relacional

(SNA)

3 Metodologia 51

3.1 Objetivo e delimitação do estudo $\quad 51$

3.2 Tipo de pesquisa $\quad 52$

3.2.1 Quantos aos fins $\quad 52$

3.2.2 Quantos aos meios $\quad 52$

3.3 Seleção de sujeitos $\quad 54$

3.4 Fontes para a revisão da literatura 56

$\begin{array}{ll}3.5 \text { Coleta de dados } & 56\end{array}$

$\begin{array}{ll}\text { 3.5.1 Pesquisa documental } & 57\end{array}$

3.5.2 Pesquisa telematizada $\quad 57$

3.5.3 Levantamento de percepções por meio de questionário 58

3.5.4 Levantamento complementar $\quad 59$

3.5.5 Levantamento de percepções dos parceiros $\quad 59$

$\begin{array}{ll}3.6 \text { Tratamento dos dados } & 60\end{array}$

3.7 Limitações metodológicas $\quad 64$

4 Resultados $\quad 65$

4.1 Contextualização da Pesquisa 65

4.1.1 Histórico da Petrobras $\quad 65$

4.1.2 Histórico da responsabilidade sócio-ambiental na

$\begin{array}{ll}\text { Petrobras } & 68\end{array}$

$\begin{array}{ll}4.2 \text { Resultados } & 70\end{array}$

4.2.1 Estratégia da Petrobras 70 
4.2.2 Fatores macroambientais e atores-chave 76

4.2.3 Fatores organizacionais 99

$\begin{array}{lr}4.2 .4 \text { Alianças estratégicas } & 116\end{array}$

4.2.5 Implicações estratégicas da ego-rede 123

$\begin{array}{ll}\text { 4.2.6 Levantamento de percepções dos parceiros } & 130\end{array}$

5 Discussão 133

5.1 Análise da adequação estratégica com abordagem

$\begin{array}{ll}5.2 \text { Fontes de inconsistências e propostas de mudanças } & 141\end{array}$

6 Conclusão 145

7 Referências Bibliográficas $\quad 148$

8 Anexos 154 


\section{Lista de Figuras}

Figura 1 - Evolução do modelo Macedo-Soares, 2000

Figura 2 - Representação esquemática de uma ego-rede hipotética

Figura 3 - Metodologia para construção do questionário

46

Figura 4 - Estrutura organizacional da Petrobras

Figura 5 - Diretrizes estratégicas da Petrobras 73

Figura 6 - Capital votante da Petrobras $\quad 74$

Figura 7 - Capital não-votante da Petrobras $\quad 74$

Figura 8 - Capital social da Petrobras $\quad 74$

Figura 9 - Esquema simplificado do processo de planejamento estratégico na Petrobras

Figura 10 - Reservas provadas de gás natural 82

Figura 11 - Consumo de gás natural 82

Figura 12 - Matriz energética brasileira $\quad 83$

Figura 13 - Fontes de energia renováveis $\quad 84$

Figura 14 - Texto divulgando a descoberta de reserva de óleo na Bacia de Campos (RJ) 84

Figura 15 - Rede de gasodutos da Petrobras na América do Sul 88

Figura 16 - Volume de vazamentos $\left(\mathrm{m}^{3}\right)$ de petróleo e derivados da Petrobras

Figura 17 - Atores estratégicos na indústria de energia e suas forças

Figura 18 - Evolução das emissões de SOX (toneladas) da Petrobras

Figura 19 - Pesquisa Omni Marketing

115

Figura 20 - Pesquisa Institutos Akatu e Ethos

115

Figura 21 - Participação das alianças como parte da estratégia da Petrobras

Figura 22 - Principais parceiros nas alianças sócio-ambientais da Petrobras

Figura 23 - Critérios de compatibilidade na busca de parceiros sócio-ambientais

Figura 24 - Tipos de alianças sócio-ambientais da Petrobras quanto ao número de parceiros

Figura 25 - Parceiros da Petrobras nas alianças sócioambientais múltiplas

Figura 26 - Percepção quanto ao volume dos recursos dos parceiros sócio-ambientais

Figura 27 - Ego-rede da Petrobras destacando suas principais alianças sócio-ambientais

Figura 28 - Impacto das alianças sócio-ambientais no desempenho da Petrobras 
Figura 31 - Caracterização da centralidade de uma empresa focal

Figura 32 - Posição da Petrobras nas redes sócio-ambientais 


\section{Lista de Tabelas}

Tabela 1 - Tipos de alianças (estratégicas ou não) conforme os critérios propostos por Tauhata (2002)

Tabela 2 - Tipos de Alianças em Função do Tipo de

Relacionamento adaptadas de Macedo-Soares e Tauhata

Tabela 3 - Novo paradigma de alianças estratégicas (Doz \& Hamel, 1998)

Tabela 4 - Dimensões das responsabilidades corporativas 29

Tabela 5 - O contínuo da colaboração intersetorial 36

Tabela 6 - Dimensões para a adequação estratégica das alianças sociais e ambientais

Tabela 7 - Características estruturais das alianças sociais e ambientais

Tabela 8 - Benefícios gerados por uma aliança social e ambiental

Tabela 9 - Atributos necessários / desejáveis para cada variável principal, no caso da gestão / implementação de estratégia voltada para a responsabilidade sócio-ambiental adaptada de Coutinho \& Macedo-Soares(2002)

Tabela 10 - Lista das dimensões fundamentais do modelo relacional

Tabela 11 - Lista de constructos e indicadores no nível da indústria adaptado de Tauhata (2002)

Tabela 12 - Lista de constructos e indicadores no nível da empresa adaptado de Tauhata (2002)

Tabela 13 - Projetos voltados para a responsabilidade sócioambiental desenvolvidos no Centro de Pesquisas da Petrobras

Tabela 14 - Fases e métodos da pesquisa

Tabela 15 - Exemplo de componentes da rede de valor da Petrobras

Tabela 16 - Implicações estratégicas dos fatores macroambientais externos à indústria de energia, considerando a responsabilidade sócio-ambiental

Tabela 17 - Impactos ambientais significativos dos principais produtos da Petrobras

Tabela 18 - Caracterização das fontes de energia renováveis

Tabela 19 - Principais acidentes com petróleo e derivados no Brasil

Tabela 20 - Atores e papéis na indústria energética, suas caracterizações e as ameaças e oportunidades representadas à empresa, considerando a responsabilidade sócio-ambiental

Tabela 21 - Recursos organizacionais da Petrobras, considerando a responsabilidade sócio-ambiental no caso da gestão / implementação de estratégia voltada para a responsabilidade sócio-ambiental

Tabela 22 - Atributos desejáveis para cada variável, 
considerando a responsabilidade sócio-ambiental no caso da gestão / implementação de estratégia voltada para a responsabilidade sócio-ambiental

Tabela 23 - Resultados dos indicadores de desempenho financeiro da Petrobras

Tabela 24 - Resultados dos indicadores de desempenho operacional da Petrobras

Tabela 25 - Resultado consolidado por público de interesse da Petrobras

Tabela 26 - Resultados dos indicadores de opinião pública da

Petrobras por tema

Tabela 27 - Fatores determinantes na busca de alianças sócioambientais pela Petrobras

Tabela 28 - Principais alianças sócio-ambientais da Petrobras e suas características

Tabela 29 - Implicações estratégicas da ego-rede sócioambiental da Petrobras, no nível da indústria

Tabela 30 - Implicações estratégicas da ego-rede sócioambiental da Petrobras, no nível da empresa

Tabela 31 - Implicações estratégicas da ego-rede sócioambiental da Petrobras, no nível da empresa, após o levantamento de percepções dos parceiros

Tabela 32 - Confronto de implicações estratégicas Análise Relacional versus Tradicional, quanto às oportunidades e ameaças constituídas pelos fatores macroambientais e pelos agentes que integram a ego-rede, considerando a responsabilidade sócio-ambiental

Tabela 33 - Contribuições do modelo SNA em relação à análise tradicional (modelo GI), quanto às forças e fraquezas constituídas pelos fatores organizacionais e pela ego-rede, considerando a responsabilidade sócio-ambiental 